\title{
Thermal Degradation Behavior of Polyvinyl Alcohol/Starch/Carboxymethyl Cellulose/ Clay Nanocomposites
}

\author{
Mohammad Taghi Taghizadeh, Narges Sabouri* \\ Department of Physical chemistry, Faculty of Chemistry, University of Tabriz, P.O. Box 51666-16471, Tabriz, Iran \\ *Corresponding Author: narges.sabouri60@gmail.com
}

Copyright (C) 2013 Horizon Research Publishing All rights reserved.

\begin{abstract}
Polyvinyl alcohol (PVA) / starch (S) /Carboxy methyl cellulose (CMC) / Montmorillonite (MMT) bionanocomposite films were prepared from PVA, MMT, CMC and soluble starch aqueous suspensions by casting method in the presence of a plasticizer that contained glycerol. The kinetics of thermal degradation of $\mathrm{PVA} / \mathrm{S} / \mathrm{CMC} / \mathrm{MMT}$ blends was investigated by thermogravimetry (TGA) and derivative thermogravimetry (DTG). Experiments under non-isothermal conditions were carried out for samples in nitrogen (the inert atmosphere in order to avoid thermoxidative degradation) at heating rates of $7.5,10$ and $150 \mathrm{C} / \mathrm{min}$. The Ozawa method was used to calculate the activation energy of thermal degradation for $\mathrm{PVA} / \mathrm{S} / \mathrm{CMC}$ and PVA/S/CMC/MMT blends. The thermal stability of PVA/S/CMC/MMT blends is higher than that of $\mathrm{PVA} / \mathrm{S} / \mathrm{CMC}$ suggesting that the addition of MMT improved the thermal stability of PVA/S/CMC blend. At least four degradation distinct stages were identified in the PVA/S/CMC/MMT blends by means of using TGA, being assigned to the mass loss due to the plasticizer leaching, and to the degradation of the starch, CMC and PVA fractions.
\end{abstract}

Keywords Thermogravimetry, Thermal Stability, Montmorillonite, Clay, Nanocomposite

\section{Introduction}

Nano-biocomposites are a new class of hybrid materials composed of nano-sized filler (nanofiller) incorporated into a bio-based matrix [1]. Such an association between eco-friendly biopolymers and nano-objects, with the aim to obtain synergic effects, is one of the most innovating routes to enhance the properties of these bio-matrices [2]. Depending on the geometry and the nature of the nanofiller, new and/or improved properties (gas barrier, mechanical stiffness, transparency, thermal stability. .) can be obtained $[1,3]$. Such properties enhancements rely both on the nanofiller geometry and on its surface area, which is directly linked to the nanofiller dispersion state. In the case of layered silicates (e.g. montmorillonite), depending on the process conditions and on the matrix/nanofiller affinity, the clay platelets can either be intercalated by macromolecules and/or exfoliated, leading to different behaviors. Intercalated structures show regularly alternating silicate layers and polymer chains compared to exfoliated structures in which the clay platelets are individually delaminated and fully dispersed into the polymer matrix. The best performances are commonly observed with the latter structure $[1,2]$. The thermoplastic starch or plasticized starch is obtained after disruption and plasticization of native starch, by temperature and in presence of water and another plasticizer, such as glycerol. However, the thermoplastic starch has some limitations: it is mostly water-soluble and has poor resistance and low strength. The resistance to water may be improved by adding certain synthetic polymers [4], such as polyvinyl alcohol and natural polymers [5], such as lignin or carboxy methyl cellulose. PVA has been used previously in extruded thermoplastic starch to improve properties such as elongation and process ability (predominantly through improving melt strength) [6-8]. Carboxy methyl cellulose is cellulose ether which exhibits thermal gelation and forms excellent films. Because of its polymeric structure and high molecular weight, it can be used as filler in biocomposite film production. Carboxy methyl cellulose can improve the mechanical and barrier properties of starch-based films [9]. In addition, it is possible to improve the mechanical properties of this polymer by adding fillers. These composites could be used in packaging where good barrier and thermal properties are required [10-12]. Development of the polymer/clay nanocomposites is one of the latest revolutionary steps of the polymer technology. Preparations of blends or nanocomposites using inorganic or natural fibers are among the routes to improve some of the properties of biodegradable polymers. Recent researches [13-17] have proved potential of organoclays for starch-based polymer nanocomposites to improve the long-term mechanical 
properties over the unfilled formulations. The aim for the addition of clay minerals to the polymers is to improve the polymer properties and to produce the polymer/clay nanocomposites with demand characteristics for desired applications. Almost it is wanted to obtain a nanocomposite with demand properties and characters or overcome the drawbacks of polymers while remaining the intrinsic advantages of primary polymer matrix. Because of the low price, availability, high aspect ratio as well as desirable nanostructure and interfacial interactions, clays can provide dramatic and adjustable improved properties at very lower loadings which help to the more remaining of polymer original useful properties. The nature and properties of components as well as preparation methodology and conditions affects on the final properties of polymer/clay nanocomposite [18]. In this section the various improved properties of polymer/clay nanocomposites as well as the mechanism and effective parameters are discussed. Thermal stability of polymer/clay nanocomposites have been analyzed and compared with that of pure polymer under various oxidative (air) or non-oxidative (inert gases) conditions. Thermogravimetric analysis (TGA) has been usually used to evaluate the thermal stability of polymer and their nanocomposites. In this technique, the weight loss of the material due to the formation of volatile compounds under degradation because of the heating and temperature rising is monitored. In general, it has been reported that the polymer/clay nanocomposites are thermally more stable than pure polymers $[19,20]$.

That is the incorporation of clay fillers into the polymer matrices results to the improvement of their thermal stability. The effect of clay layers has been more explained as superior insulation and mass transport barrier against the volatile compounds generated during the decomposition of polymer under thermal conditions [21]. Also it has been reported that clays assist in the formation of layered carbonaceous char during degradation of polymer/clay nanocomposite [1]. Clay minerals are inorganic materials and are almost stable in the temperature ranges that organic polymers are degraded in to volatile compounds. Therefore in TGA experiments the clay content of nanocomposites is remain as residue after heating program [22]. Blumstein first reported the improved thermal stability of PMMA/MMT nanocomposite. TGA showed that PMMA intercalated into the Na-MMT has $40-50{ }^{\circ} \mathrm{C}$ higher decomposition temperature [23]. Vyazovkin et al. [24] reported the thermal stability of polystyrene/clay nano-composite compared to pure PS. They have showed that PS/clay nanocomposites have $30-40{ }^{\circ} \mathrm{C}$ higher degradation temperature compared to pure PS under nitrogen and air heating degradation conditions. Other studies have been showed that the nature of the clay modifier can affect on the thermal stability of modified clay and related nanocomposites [25]. The understanding of their thermal stability and degradation has importance in processing and recycling. Thermal degradation of PVA [26, 27] and PVA/S was recently studied $[28,29]$. The main goal of this paper is to evaluate the effect MMT on the PVA/S/CMC blends thermal degradation or study of thermal degradation of PVA/S/CMC/MMT blends. Thermal analysis of the mixtures was performed by TG/DTG under dynamic conditions. The calculation of apparent activation energies was based on the application the kinetic model proposed by Ozawa [30-32].

\section{Experimental}

\subsection{Materials}

Soluble starch (ST) was provided by Merck company, and polyvinyl alcohol with $M_{n}=72000$ and glycerol $\left(M_{n}=92 / 10\right.$, grade of pure $78 \%$ ) purchased from Merck company. Carboxy methyl cellulose sodium salt, with an average molecular weight of $M_{n}=295225$ was purchased from Fluka company. Sodium montmorillonite $\left(\right.$ Cloisite $\left.\mathrm{Na}^{+}\right)$with a cation exchange capacity (CEC) of 92.6 mequiv. /100 g clay was supplied by Nanocor Inc. (Arlington Heights, IL).

\subsection{Preparation of Films}

Films were obtained by casting method [34, 35]. First, PVA $(2.5 \mathrm{~g})$ was solubilized in $50 \mathrm{ml}$ of distilled water at $75^{\circ} \mathrm{C}$ for $15 \mathrm{~min}$ and starch $(2.5,2,1.5 \mathrm{~g})$ was mixed $\left(25^{\circ} \mathrm{C}\right.$ for $10 \mathrm{~min})$ with distilled water $(15 \mathrm{ml})$. Then, glycerol (40 $\mathrm{ml} / 100 \mathrm{~g}$ starch) was added to $20 \mathrm{ml}$ of boiling water to obtain a clear solution. Carboxy methyl cellulose $(0,0.5,1 \mathrm{~g})$ was solubilized in $75 \mathrm{ml}$ of distilled water at $75^{\circ} \mathrm{C}$ for $15 \mathrm{~min}$. On the other hand, the montmorillonite (MMT) was dispersed in $35 \mathrm{cc}$ distilled water by sonication for $10 \mathrm{~min}$ at room temperature. The clay ratios were $0,1,3$ and $5(\mathrm{w} / \mathrm{w})$, relative to dry blend. Then, PVA, starch, CMC and MMT solutions were mixed together and stirred with by a magnetic bar at $75^{\circ} \mathrm{C}$ for $90 \mathrm{~min}$ with a reflux condenser. Then, about $70 \mathrm{ml}$ of the sample was poured into a Teflon casting tray resulting in films with $0.08 \pm 0.01 \mathrm{~mm}$ thickness, measured with an Alton M820-25 hand-held micrometer with a sensitivity of $0.01 \mathrm{~mm}$ and then dried at $60^{\circ} \mathrm{C}$ in oven to cast the films.

\subsection{Thermal Analysis}

Thermogravimetry was carried out using a Perkin Elmer pyris diamond TG-DTA instrument at various heating rates (7.5-15 ${ }^{0} \mathrm{C} \mathrm{min}^{-1}$ ) under inert atmosphere (nitrogen environment) in order to avoid thermoxidative degradation. Temperature programs for dynamic tests were run from 0 to $600^{\circ} \mathrm{C}$ at different heating rates, between 7.5 and $15{ }^{\circ} \mathrm{C}$. $\min ^{-1}$.

\subsection{Scanning Electronic Microscopy (SEM)}

The morphology of the surface of the films was investigated using a scanning electronic microscope of XL30 type (Netherland). The films were covered with pure metalic Ag. The laying down of $\mathrm{Ag}$ was carried out using 
evaporation of the metal under a high vacuum, to give a thickness of around $100 \mathrm{~A}^{\circ}$.

\section{Theoretical Approach}

The application of dynamic TGA methods holds great promise as a tool for unveiling the mechanisms of physical and chemical processes that occur during polymer degradation. A reaction rate can be defined as the derivative of the conversion with respect to time.

Thermogravimetric analysis (TGA) has come into wide use in the last decades for rapidly assessing the thermal stability of various substances. The trace follows a characteristic path common to a wide range of decompositions; including many polymer pyrolysis [30]. The sample weight drops slowly as pyrolysis begins; then drops precipitously over a narrow range and finally turns back to zero slopes as the reactant is exhausted.

The shape of the curve is determined by the kinetic parameters of the pyrolysis such as; reaction order, frequency factor; and activation energy [36]. The derivation of kinetic data in the study of polymer decomposition using TGA has received increasing attention in the last decade; along with much criticism regarding its use in the determination of rate constants; activation energies; reaction orders and Arrhenius pre-exponential constants [37]. The values obtained depend upon atmosphere; sample mass; sample shape; flow rate; heating rate but also on the mathematical treatment used to evaluate the data. The data obtained by TGA have been studied using a variety of techniques. In the kinetic methods, the following symbols are usual [31]: Ea: apparent activation energy $(\mathrm{kJ} / \mathrm{mol}), \mathrm{A}$ : pre-exponential factor (min-1), n: apparent order of reaction, $\mathrm{R}$ : universal gas constant $(8.3136 \mathrm{~J} / \mathrm{K} . \mathrm{mol})$, T: temperature $(\mathrm{K}), \alpha$ : degree of conversion or fractional mass loss, $\mathrm{t}$ : time ( $\mathrm{min}), \beta$ : heating rate $(0 \mathrm{C} / \mathrm{min})$, and $\mathrm{k}$ : rate constant (s-1).

All kinetic studies utilize the basic rate equation:

$$
\mathrm{d} \alpha / \mathrm{dt}=\mathrm{k} . \mathrm{f}(\alpha)
$$

Eq. (1) expresses the rate of conversion, $d \alpha / \mathrm{dt}$, at a constant temperature as a function of the reactant concentration loss and rate constant.

In TGA, the conversion $[\alpha(t)]$ is defined as the ratio of the mass loss at time $t$ to the total mass loss corresponding to a particular stage of degradation:

$$
\alpha(t)=\left[w_{0}-w_{t}\right] /\left[w_{0}-w_{\infty}\right]
$$

where $\mathrm{w}_{0}, \mathrm{w}_{(\mathrm{t})}$, and $\mathrm{w}_{\infty}$ are the initial mass of the sample, the sample mass at time $t$, and the sample mass at infinite time (i.e., 0 ), respectively.

In the case of polymer degradation, it is assumed that the rate of conversion is proportional to the concentration of material that has to react.

$$
f(\alpha)=(1-\alpha)^{n}
$$

The combination of these equations and the empirical Arrhenius expression gives the following relationship:

$$
\mathrm{d} \alpha / \mathrm{dt}=\mathrm{A} \cdot(1-\alpha)^{\mathrm{n}} \cdot \exp (-\mathrm{Ea} / \mathrm{RT})
$$

Introducing the heating rate, $\beta$ into Eq. (4):

$$
\mathrm{d} \alpha /(1-\alpha)^{\mathrm{n}}=(\mathrm{A} / \beta) \cdot \exp (-\mathrm{Ea} / \mathrm{RT}) \cdot \mathrm{dT}
$$

This is the fundamental expression of analytical methods to calculate kinetic parameters on the basis of TGA data.

In the Table 1, the most common methods are summarized [32]

\section{Results and Discussion}

\subsection{Thermal Properties}

The TGA and DTG curves for PVA/S/CMC and $\mathrm{PVA} / \mathrm{S} / \mathrm{CMC} / \mathrm{MMT} 1 \%$ blends at heating rate $10^{\circ} \mathrm{C} / \mathrm{min}$ are shown in Figures 1 and 2.

The DTG curves show the degradation rate of the samples. It can be seen that both PVA/S/CMC and $\mathrm{PVA} / \mathrm{S} / \mathrm{CMC} / \mathrm{MMT}$ blends exhibited a four-step degradation pattern. As samples contain a small quantity of water (water of free), the first stages of degradation (up to about $90^{\circ} \mathrm{C}$ ) represent the evaporation of the water of degraded components. The second stages of degradation (up to about $220^{\circ} \mathrm{C}$ ) represent the volatilization of the easily degraded components such as glycerol [38]. The major mass loss took place in the third step (from about 250 to $360^{\circ} \mathrm{C}$ ), and was followed by a further smaller mass loss in the fourth step (from about 380 to $440^{\circ} \mathrm{C}$ ). The third step of weight loss was predominantly the characteristic degradation of a polymer structure (water elimination of PVA, decomposition of Starch and decomposition of CMC) [26, 32]. Further heating broke down the polymer backbone (cracking of PVA) [27, 39]. Affirmatively, the third step was the predominant degradation process. Therefore, this temperature range of degradation was selected for kinetic studies. The peaks' positions of the mass loss of all these three processes (exception first peak) in all the studied blends at the different heating rate are shown in table 2 
Table 1. Most common methods to calculate kinetic parameters on the basis of TGA data

\begin{tabular}{|c|c|c|c|c|}
\hline Method & Considerations & Expression & Plots & Reference \\
\hline Kissinger & $\begin{array}{c}\text { The product } \\
\text { n. }(1-\alpha)_{m}{ }^{n-1} \text { is } \\
\text { independent of } \beta \text { and } \\
\text { very nearly equal to } 1 \\
\text { y for first order } \\
\text { reaction }\end{array}$ & $\frac{d\left(\ln \left(\frac{\beta}{T_{m}^{2}}\right)\right)}{d\left(\frac{1}{T_{m}}\right)}=\left(\frac{-E_{\mathrm{a}}}{R}\right)$ & $\begin{array}{c}\ln \left(\beta / \mathrm{T}_{\mathrm{m}}{ }^{2}\right) \\
\text { against } \\
1 / \mathrm{T}_{\mathrm{m}}\end{array}$ & {$[40]$} \\
\hline Friedman & $\begin{array}{l}\text { Comparison of mass } \\
\text { loss rates }(\mathrm{d} \alpha / \mathrm{dt}) \text { for a } \\
\text { fractional mass loss, } \alpha \text {, } \\
\text { determined using } \\
\text { different heating rates }\end{array}$ & $\ln \left(\frac{\mathrm{d} \alpha}{\mathrm{dt}}\right)=\ln A+\mathrm{n} \cdot \ln (1-\alpha)-\frac{\mathrm{E}_{\mathrm{a}}}{\mathrm{R} \cdot \mathrm{T}}$ & $\begin{array}{l}\operatorname{Ln}(\mathrm{d} \alpha / \mathrm{dt}) \\
\text { against } 1 / \mathrm{T} \\
\text { for a } \\
\text { constant } \alpha \\
\text { E/R. } \mathrm{T}_{0} \\
\text { against } \\
(1-\alpha)\end{array}$ & {$[34]$} \\
\hline $\begin{array}{c}\text { Horowitz-Metzge } \\
\mathrm{r}\end{array}$ & $\begin{array}{c}\mathrm{T}_{\mathrm{s}} \text {, temperature at } \\
\text { which } \\
\begin{array}{c}1 /(1-\alpha)=1 / \exp =0.368 \\
\Theta=T-\mathrm{T}_{\mathrm{s}} .\end{array} \\
\text { First-order kinetics }\end{array}$ & $\ln \left[\ln \left(\frac{1}{1-\alpha}\right)\right]=\left(\frac{\mathrm{E}_{\mathrm{a}}, \theta}{\mathrm{R} \cdot \mathrm{T}_{\mathrm{g}}^{2}}\right)$ & $\begin{array}{l}\operatorname{Ln} \\
\ln (1 /(1-\alpha)) \\
\text { against } \Theta\end{array}$ & [33] \\
\hline Flynn and Wall & $\begin{array}{c}\text { Several curves at } \\
\text { different heating rates }\end{array}$ & $\frac{-d \log \beta}{d\left(\frac{1}{T}\right)}=0.457 \cdot \frac{E_{a}}{R}$ & $\begin{array}{l}\mathrm{d}(\log \beta) \\
\text { against d } \\
\quad(1 / \mathrm{T})\end{array}$ & {$[33]$} \\
\hline Ozawa Method & $\begin{array}{l}\mathrm{A},(1-\alpha)^{\mathrm{n}} \text { and } \mathrm{E} \text { are } \\
\text { independent of } \mathrm{T} \\
\text { while } \mathrm{A} \text { and } \mathrm{E}_{\mathrm{a}} \text { are } \\
\text { independent of } \alpha\end{array}$ & $\log F(\alpha)=\log \left(\frac{A \cdot E_{a}}{R}\right)-\log \beta-2.315-0.4567 \cdot \frac{E_{a}}{R \cdot T}$ & $\begin{array}{c}\log \beta \\
\text { against } 1 / \mathrm{T} \\
\text { for a fixed } \\
\text { degree of } \\
\text { conversion }\end{array}$ & {$[33,34]$} \\
\hline Van Krevelen & $\begin{array}{l}\text { At a fixed temperature, } \\
\mathrm{T}_{\mathrm{m}} \text {, a maximum rate } \\
\text { can be measured }\end{array}$ & {$\left[\ln \left(\frac{1}{1-\alpha}\right)-1\right]=\ln \left[\frac{\mathrm{A}}{\beta} \cdot\left(\frac{0.368}{\mathrm{~T}_{\mathrm{m}}}\right)^{\frac{\mathrm{E}_{\mathrm{a}}}{\mathrm{RT}}} \cdot \frac{1}{\frac{\mathrm{E}_{\mathrm{a}}}{\mathrm{RT}_{\mathrm{m}}}+1}\right]+\left(\frac{E_{\alpha}}{R T_{m}}+1\right) \cdot \ln T$} & $\begin{array}{l}\quad \ln T \\
\ln (1 /(1-\alpha)) \\
\text { against } \ln T\end{array}$ & {$[33,34]$} \\
\hline Broido & & $\ln \left[\ln \left(\frac{1}{\alpha}\right)\right]=\frac{E}{\mathrm{R}}\left(\frac{1}{T}\right)+$ constant & $\begin{array}{l}\operatorname{Ln}[\ln (1 / \alpha)] \\
\text { against } 1 / \mathrm{T}\end{array}$ & {$[31,36]$} \\
\hline
\end{tabular}




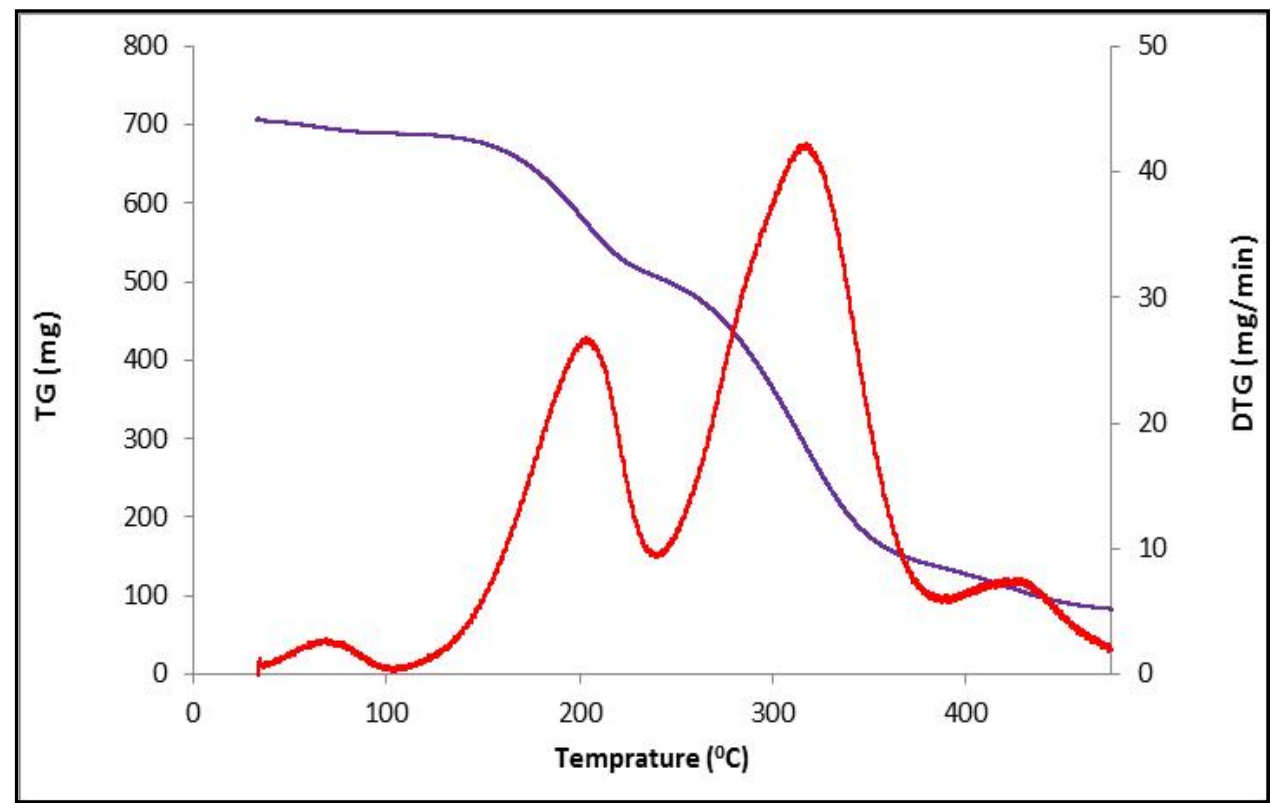

Figure 1. The TGA and DTG curves for PVA/S/CMC blend at heating rate $10^{\circ} \mathrm{C} / \mathrm{min}$

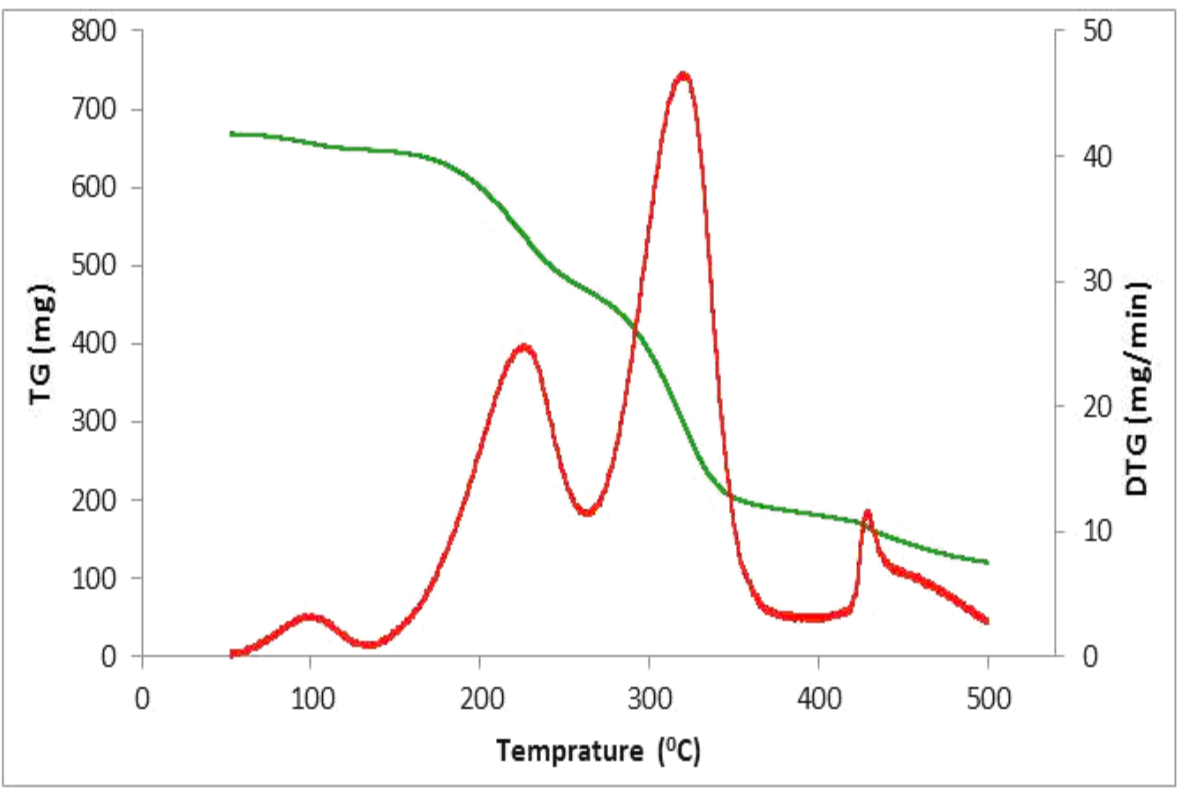

Figure 2. The TGA and DTG curves for PVA/S/CMC/MMT $1 \%$ and blends at heating rate $10^{\circ} \mathrm{C} / \mathrm{min}$

Table 2. The peaks' positions of the mass loss of all these three processes (exception first peak) in all the studied blends at the different heating rate

\begin{tabular}{|c|c|c|c|c|}
\hline Sample & PVA50-S30-CMC20 & $1 \% \mathrm{MMT}$ & 3\% MMT & $5 \% \mathrm{MMT}$ \\
\hline $7.5^{0} \mathrm{C} / \mathrm{min}$, second peak $\left({ }^{0} \mathrm{C}\right)$ & 199 & 222 & 230 & 234 \\
\hline Third peak $\left({ }^{0} \mathrm{C}\right)$ & 311 & 318 & 322 & 330 \\
\hline Fourth peak $\left({ }^{0} \mathrm{C}\right)$ & 416 & 431 & 433 & 440 \\
\hline $10^{\circ} \mathrm{C} / \mathrm{min}, \operatorname{second} \operatorname{peak}\left({ }^{0} \mathrm{C}\right)$ & 203 & 226 & 235 & 236 \\
\hline Third peak $\left({ }^{0} \mathrm{C}\right)$ & 316 & 320 & 327 & 328 \\
\hline Fourth peak $\left({ }^{0} \mathrm{C}\right)$ & 420 & 429 & 436 & 441 \\
\hline $15^{0} \mathrm{C} / \mathrm{min}$, second peak $\left({ }^{0} \mathrm{C}\right)$ & 218 & 243 & 249 & 249 \\
\hline Third peak $\left({ }^{0} \mathrm{C}\right)$ & 320 & 326 & 333 & 334 \\
\hline Fourth peak $\left({ }^{0} \mathrm{C}\right)$ & 423 & 428 & 434 & 440 \\
\hline
\end{tabular}




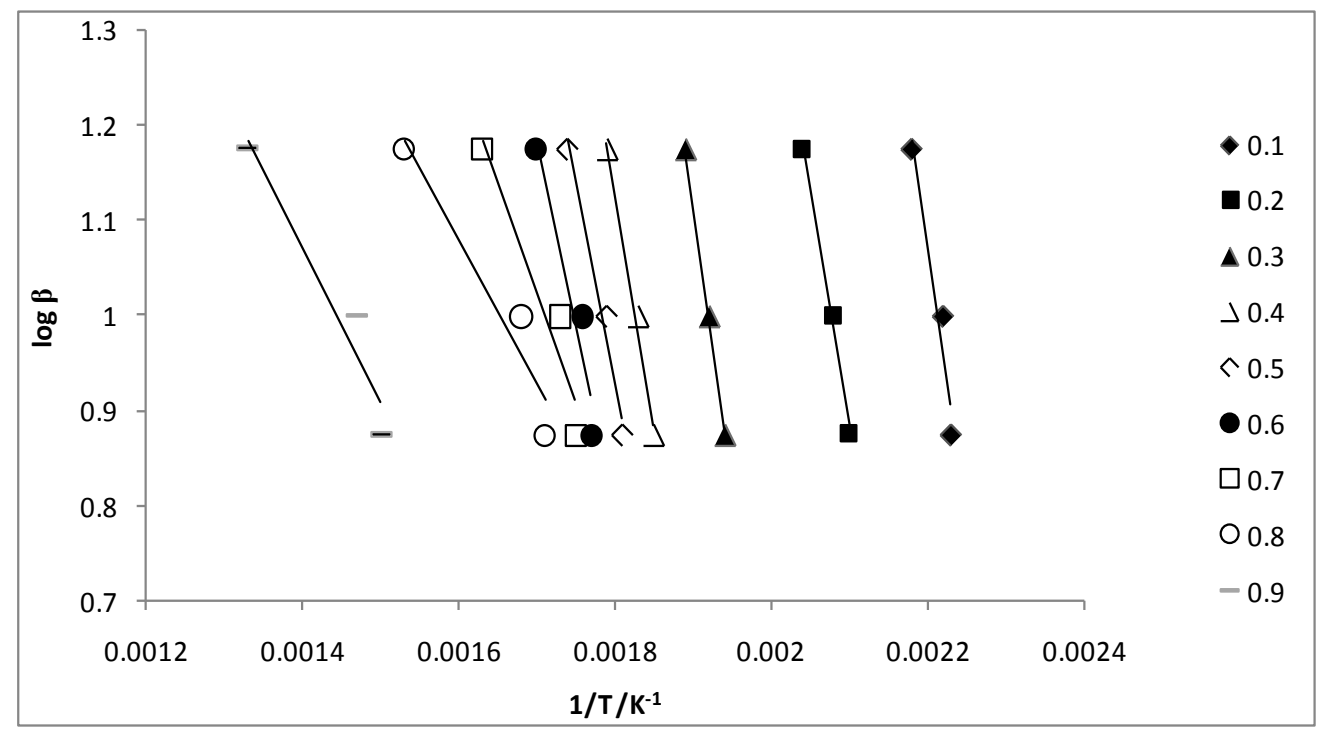

Figure 3. Application of Ozawa method to PVA/S/CMC blend for different conversion 0.1-0.9.

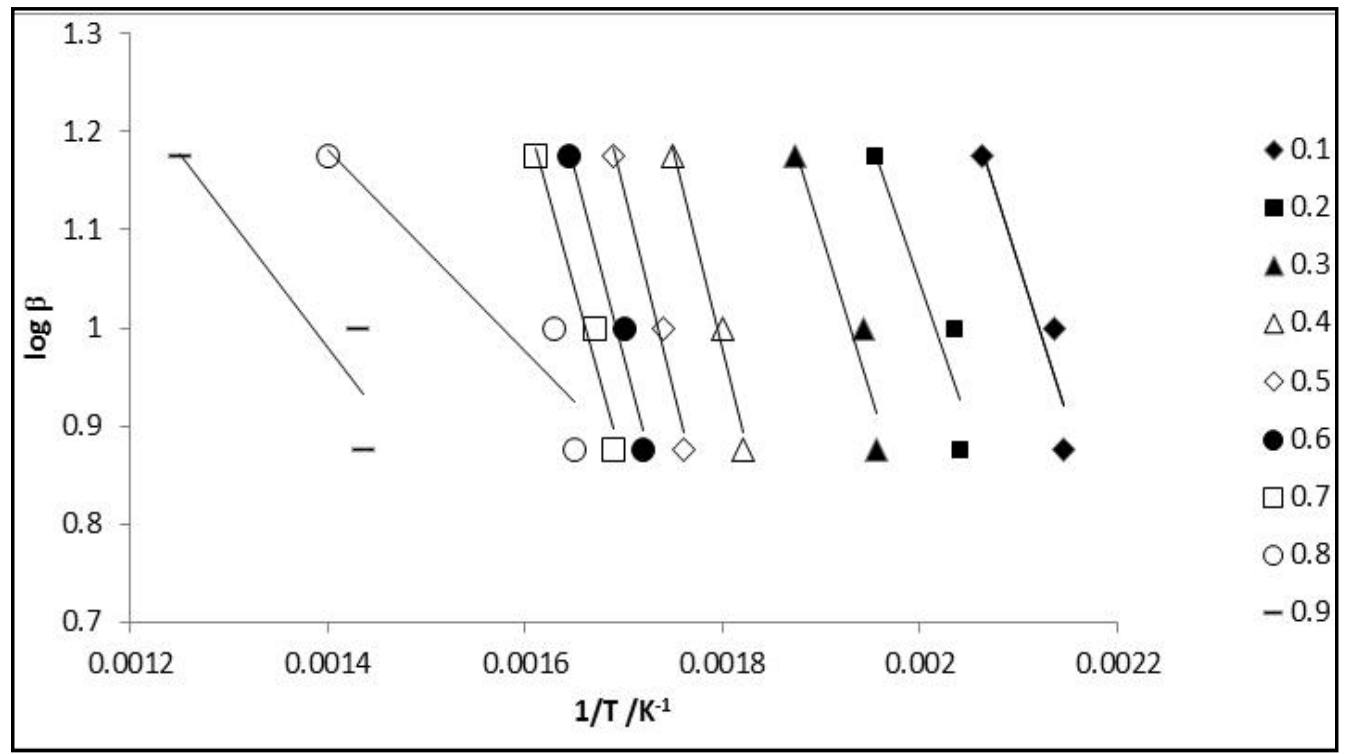

Figure 4. Application of Ozawa method to $\mathrm{PVA} / \mathrm{S} / \mathrm{CMC} / \mathrm{MMT} 1 \%$ blend for different conversion 0.1-0.9.

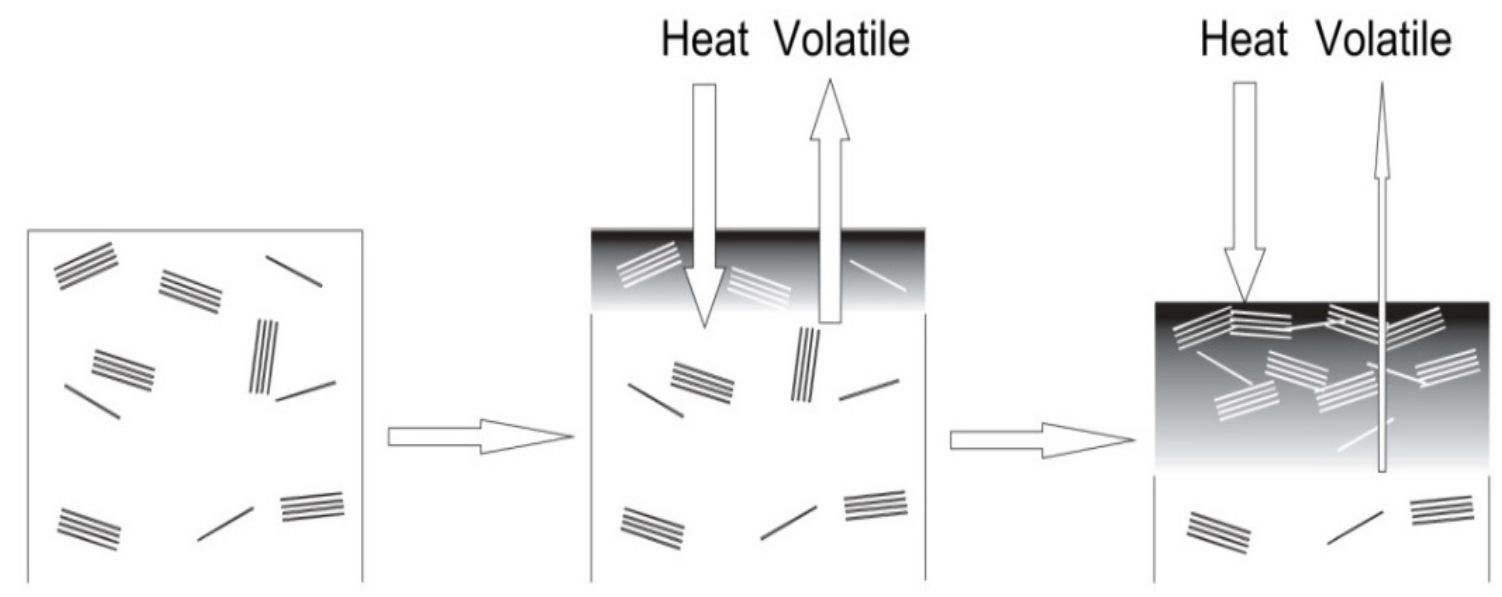

Figure 5. Schematic representation of the ablative reassembling mechanism of a nanocomposite during combustion. 


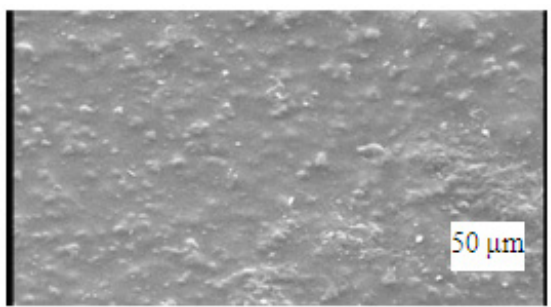

(a)

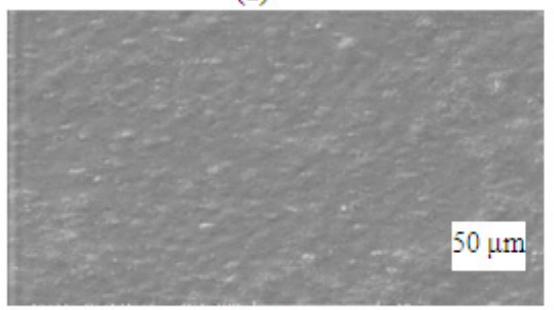

(c)

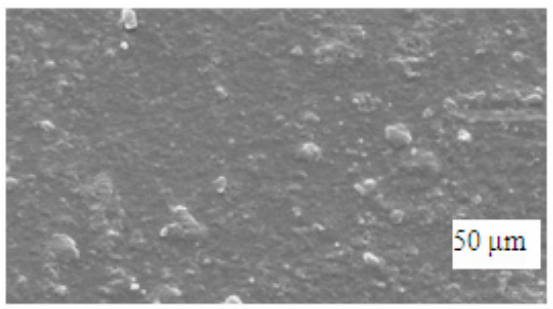

(b)

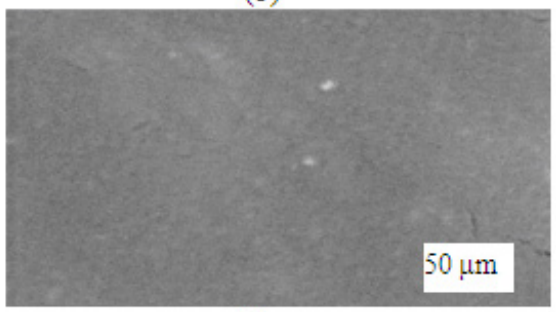

(d)

Figure 6. Scanning electron micrographs of (a) PVA:S:CMC (b) PVA:S:CMC with 1 wt $\%$ MMT; (c) PVA:S:CMC with 3 wt $\%$ MMT; (d) PVA:S:CMC with $5 \mathrm{wt} \%$ MMT.

The thermal degradation rate depends on conversion $(\alpha)$. For different reactions, the degradation rate given as a function of conversion is different and must be determined from experimental data. For a complex reaction such as polymer degradation, the function of conversion is generally complicated and unknown. In these cases, we used the model free kinetic method such as the Ozawa equation to study the complex degradations of PVA/S/CMC and $\mathrm{PVA} / \mathrm{S} / \mathrm{CMC} / \mathrm{MMT}$ blends. The Ozawa method was employed to analyze the TGA data of PVA/S/CMC and PVA/S/CMC/MMT1\% blends. By using Equation Ozawa, the activation energy of degradation can be obtained from the plot of $\log [\beta]$ vs. $1 / \mathrm{T}$. The results were plotted in Figures 3 and 4 respectively.

The activation energy (E) values of all the blends calculated by Ozawa equation are tabulated in table 3 .

Table 3. The activation energy (E) values of all the blends calculated by Ozawa equation

\begin{tabular}{cc}
\hline method & Ozawa \\
\hline sample & $\mathrm{E}(\mathrm{kj} / \mathrm{mol}),\left(250-350^{\circ} \mathrm{C}\right)$ \\
\hline PVA50/S30/CMC20 & 69 \\
\hline PVA50/S30/CMC20/1\%MMT & 71 \\
\hline PVA50/S30/CMC20/3\%MMT & 74 \\
\hline PVA50/S30/CMC20/5\%MMT & 76 \\
\hline
\end{tabular}

The activation energy of $\mathrm{PVA} / \mathrm{S} / \mathrm{CMC} / \mathrm{MMT}$ blends is higher than that of PVA/S/CMC. Obviously; the MMT dramatically improved the thermal stability of PVA/S/CMC blends. The behavior of the nanocomposite during combustion is thus explainable with a general mechanism as reported in Figure 5. [20, 21]. Heat transfer from an external source or from the flame promotes thermal decomposition of the organoclay and the polymer. This results in accumulation and reassembly of clay platelets on the surface of the burning material. This silicate structure acts as an excellent insulator and mass transport barrier that slows the escape of the volatile product generated during decomposition. This suggested that the addition of MMT improved the thermal stability of PVA/S/CMC films.

\subsection{Scanning Electronic Microscopy (SEM)}

Several scanning electronic microscopy images of nanocomposites are given in Fig. 6. In order to compare changes on surface morphology, Fig. 6 shows the differences between the films with different content of MMT. Porosity, roughness and heterogeneity surfaces decreased as a function of content MMT-Na.

\section{Conclusions}

The thermal degradation of PVA/S/CMC and $\mathrm{PVA} / \mathrm{S} / \mathrm{CMC} / \mathrm{MMT}$ blends was divided into four stages. The third stage was the principal degradation process. The calculation of the activation energy of degradation was based on this stage. For PVA/S/CMC and PVA/S/CMC/MMT, the activation energy of degradation obtained by the Ozawa method. The results obtained from the method chosen in this study suggested that the addition of MMT improved the thermal stability of PVA/S/CMC films. PVA:S:CMC with 5 wt $\%$ MMT has best thermal stability because has higher content of MMT. Since the clay layers in the nanocomposite act as a barrier to heat and mass transfer, the degradation pathway of nanocomposite has been changed which become significant at higher concentration of clay because the degrading composite is retained by the clay layers, permitting further reaction, cause the retention of the degradation products for a longer period of time and higher temprature. Thus in higher concentrations of MMT, this effect is greater. 
With considering these results, it seems that the $\mathrm{PVA} / \mathrm{S} / \mathrm{CMC} / \mathrm{MMT}$ biocomposite films show better thermal properties than $\mathrm{PVA} / \mathrm{S} / \mathrm{CMC}$ films and can be potentially replaced of PVA/S/CMC films.

\section{Acknowledgements}

We are grateful to University of Tabriz Research Council for the financial support of this research.

\section{REFERENCES}

[1] Ray, S. S, M. Okamoto, 2003. Polymer/layered silicate nanocomposites: A review from preparation to processing. Progress in Polymer Science, 28(11):1539-1641.

[2] Alexandre, M., P. Dubois, 2000. Polymer-layered silicate nanocomposites: Preparation, properties and uses of a new class of materials. Materials Science and Engineering R-reports, 28(1): 1-63.

[3] Gain,O., E. Espuche, E. Pollet, M. Alexandre, P. Dubois, 2005. Gas barrier properties of poly(e-caprolactone)/clay nanocomposites: Influence of the morphology and polymer/clay interactions. Journal Polymer Science Part B: Polymer Physics, 43(2): 205-214.

[4] Bastioli, C., 1995. Starch Polymer Composites, In Degradable Polymer. Berlin, Cambridge. P.P. 112.

[5] Baumberg, S., C. Lapierre, B. Monties, C. Della Valle, 1998. Use of kraft lignin as filler for starch films. Polymer Degradation Stability, 59: 273-277.

[6] Mao, L., S. Imam, S. Gordon, P. Cinelli, 2000. Extruded cornstarch-glycerol-polyvinyl alcohol blends: mechanical properties, morphology, and biodegradability. Journal of Polymer Environment, 8(4): 205-211.

[7] Follain, N., C. Joly, P. Dole, C. Bliard, 2005. Properties of starch based blends, Part 2. Influence of poly vinyl alcohol addition and photocrosslinking on starch based materials mechanical properties. Carbohydrate Polymers, 60: 185-92.

[8] Fishman, M., D. Coffin, C. Onwulata, 2006. Two stage extrusion of plasticized pectin/poly(vinyl alcohol) blends. Carbohydrate Polymers, 65: 421-429.

[9] Ma, X., P.R., Chang, J. Yu, 2008. Properties of biodegradable thermoplastic pea starch/carboxymethyl cellulose and pea starch/microcrystalline cellulose composites. Carbohydrate Polymers, 72: 369-375.

[10] Plackett, D., A. Vazquez, 2004. Green composites, Polymer composites and the environmental. In Caroline Baillie (Ed.), Chapter 7: Natural Polymer Source. Washington, DC. Cambridge, England: CRC Press, p.p. 123.

[11] Singh, R. P., J.K., Pandey, D. Rutot, Ph., Degee, Ph., Dubois, 2003. Biodegradation of poly(e-caprolactone)/starch blends and composites in composting and culture environments: the effect of compatibilization on the inherent biodegradability of the host polymer. Carbohydrate Research, 338(17): 1759-1769.
[12] Svensson, E., A. Eliasson, 1995. Crystalline changes in native wheat and potato starches at intermediate water levels during gelatinization. Carbohydrate Polymers, 26: 171-176.

[13] Chivrac, F., O. Gueguen, E. Pollet, S. Ahzi, A. Makradi, L. Averous, 2008. Micromechanical modeling and characterization of the effective properties in starch based nano-biocomposites. Acta Biomaterialia, 4(6): 1707-1714.

[14] Chivrac, F., E. Pollet, L. Averous, 2009. Shear induced clay organo-modification: Application to plasticized starch nano-biocomposites. Polymers for Advanced Technologies, a; doi:10.1002/pat.1468.

[15] Chivrac, F., E. Pollet, M. Schmutz, L. Averous, 2008. New approach to elaborate exfoliated starch-based nanobiocomposites. Biomacromolecules, 9(3): 896-900.

[16] Chivrac, F., E. Pollet, M. Schmutz, L. Averous, 2010. Starch nano-biocomposites based on needle-like sepiolite clays. Carbohydrate Polymers, 80(1): 145-153.

[17] Cyras, V. P., L. B., Manfredi, M. Ton-That, A. Vazquez, 2008. Physical and mechanical properties of thermoplastic starch/montmorillonite nanocomposite films. Carbohydrate Polymers, 73(1): 55-63.

[18] Ray, S. S., 2010. A new possibility for microstructural investigation of clay-based polymer nanocomposite by focused ion beam tomography. Polymer, 51: 3966-3970.

[19] Becker, O., R. J., Varley, G. P., Simon, 2004. Thermal stability and water uptake of high performance epoxy layered silicate nanocomposites. European Polymer Journal, 40: $187-195$.

[20] Zanetti, M., P. Bracco, L. Costa, 2004. Thermal degradation behavior of PE/clay nanocomposites. Polymer Degradation and Stability, 85: 657-665.

[21] Zhu, J., F. M. Uhl, A. B. Morgan, C. A. Wilkie, 2001. Studies on the mechanism by which the formation of nanocomposites enhances thermal stability. Chemical Material, 13: 4649-4654.

[22] Gilman, J. W., 1999. Flammability and thermal stability studies of polymer layered-silicate (clay) nanocomposites. Applied Clay Science, 15: 31-49.

[23] Blumstein, A., 1965. Polymerization of adsorbed monolayers: II. Thermal degradation of the inserted polymers. Journal of Polymer Science A, 3: 2665-2670.

[24] Vyazovkin, S., I. Dranka, X. Fan, R. Advincula, 2004. Kinetics of the thermal and thermo-oxidative degradation of a polystyrene-clay nanocomposite. Macromolecular Rapid Communications, 25: 498-503.

[25] Mittal, V., 2007. Polypropylene-layered silicate nanocomposites: Filler matrix interactions and mechanical properties. Thermoplastic Composite Material, 20: 575-599.

[26] Holland, B. J., J. N. Hay, 2001. The thermal degradation of poly(vinyl alcohol). Polymer, 42: 6775-6783.

[27] Thomas, P. S., J. P. Guerbois, G. F. Russell, B. J. Briscoe, 2001. FTIR STUDY OF THE THERMAL DEGRADATION OF POLY (VINYL ALCOHOL). Journal of Thermal Analysis and Calorimetry, 64: 501-508.

[28] Sreedhar, B., D. K. Chattopadhyay, M. Sri Hari Karunakar, 
2006. Thermal and Surface Characterization of Plasticized Starch Polyvinyl Alcohol Blends Crosslinked with Epichlorohydrin. Journal of Applied Polymer Science, 101: $25-34$.

[29] Gomez, P. P., D. F. Coral, D. Ramos-Rivera, A. Rosales-Rivera, 2011. Thermo-alkaline treatment, A process that changes the thermal properties of corn starch. Procedia Food Science1, $370-378$.

[30] Lee, W. F., 1989. Comparative study of various methods for thermal degradation of poly (3-dymethyl (metacryloyoxyethyl) ammonium propanesulfonate). Applied Polymer Science, 37: 3263-3275.

[31] Jimenez, A., J. L. Berenguer, A. Sanchez, 1993. Thermal degradation study of poly (vinylchloride): kinetic analysis of thermogravimetric data. Applied Polymer Science, 50: $1565-1573$.

[32] Alvarez, V. A., A. Vazquez, 2004. Thermal degradation of cellulose derivatives/starch blends and sisal fibre biocomposites. Polymer Degradation and Stability, 84: $13-21$.

[33] Broido, A., 1969. A simple, sensitive graphical method of treating thermogravimetric analysis data. Journal of polymer Science: A-2, Polymer Physics, 7(10): 1761-1773.

[34] Yoon, S. D., S. H. Chough, H. R. Park, 2006. Properties of
Starch based Blend Films using Citric Acid as Additive. Applied Polymer Science, 100: 2554-2560.

[35] Taghizadeh, M. T., N. Sabouri, B. Ghanbarzadeh, 2012. Physical and mechanical properties of polyvinyl alcohol/starch/carboxy methyl cellulose/montmorillonite nanocomposite films. Nano Science and Nano Technology, an Indian Journal, 6(2): 54-60.

[36] Horowitz, H. H., G. Metzger, 1963. A new analysis of thermogravimetric traces. Analytical Chemistry, 35(10): 1464-1468.

[37] Cooney, J. D., M. Day, D. M. Wiles, 1983. Thermal degradation of poly (ethylene terephthalate): a kinetic analysis of thermogravimetric data. Applied Polymer Science, 28: 2887-2902.

[38] Vega, D., M. A. Villar, M. D. Failla, E. M. Valles, 1996. THERMOGRAVIMETRIC ANALYSIS OF STARCH-BASED BIODEGRADABLE BLENDS. Polymer Bulletin, 37: 229-235.

[39] Zhou, X. Y., D. M. Jia, Y. F. Cui, D. Xie, 2009. Kinetics Analysis of Thermal Degradation Reaction of PVA and PVA/Starch Blends. Journal of Reinforced Plastics and Composites, 28(22): 2771-2780.

[40] Kissinger, H. E., 1957. Reactions kinetics in differential thermal analysis. Analytical Chemistry, 29(11): 1702-1706. 